\title{
3D-networked carbon nanotube/diamond core-shell nanowires for enhanced electrochemical performance
}

\author{
Seung-Koo Lee ${ }^{1,4}$, Min-Jung Song ${ }^{2,4}$, Jong-Hoon Kim ${ }^{1}$, Tae-Seok Kan ${ }^{1}$, Young-Kyun Lim ${ }^{1}$, \\ Jae-Pyoung $\mathrm{Ahn}^{3}$ and Dae-Soon $\mathrm{Lim}^{1}$
}

\begin{abstract}
A boron-doped diamond/carbon nanotube (BDD-CNT) hybrid material with a core-shell three-dimensional random network structure was fabricated using the electrostatic self-assembly of nanodiamond. In general, CNTs are easily etched out as hydrocarbons or transformed to graphitic clusters at defect sites in hydrogen-rich environments (that is, the typical conditions employed for diamond deposition). However, attaching a dense layer of nanodiamond particles to the outer wall of the CNTs suppressed CNT etching and promoted BDD growth. To attach the dispersed nanodiamond particles on the CNT surface, we used an electrostatic self-assembly technique in which the surface charges on the CNTs and the nanodiamond were controlled using cationic and anionic polymers. Following BDD deposition, the electrochemical properties of the BDD-CNT structures were examined by cyclic voltammetry and electrochemical impedance spectroscopy. The results indicated that the BDD-CNTs exhibited enhanced electron transport efficiency, large effective surface areas and high sensitivity, with a remarkably low detection limit.
\end{abstract}

NPG Asia Materials (2014) 6, e115; doi:10.1038/am.2014.50; published online 25 July 2014

\section{INTRODUCTION}

Due to its excellent properties, boron-doped diamond (BDD) has attracted considerable attention as an active electrode material for various applications. ${ }^{1-3}$ The electrochemical properties of $\mathrm{BDD},{ }^{4-10}$ such as its wide potential window, low background current, reversible to quasi-reversible electron transfer kinetics, enhanced signal-to-noise ratio, long-term stability and biocompatibility, make it a potential candidate for next-generation electrochemical sensor platforms.

The electrochemical performance of a BDD electrode is significantly affected by its surface structure. Doped diamond has been modified by various methods such as plasma treatment, ${ }^{11,12}$ the deposition of nanoparticles, ${ }^{13,14}$ the deposition of thin films ${ }^{15,16}$ and metal ion implantation. ${ }^{17}$ Modified electrodes are expected to be advantageous in comparison with conventional electrodes; however, modified BDD electrodes may sacrifice the ideal characteristics of diamond because the diamond surfaces are covered or modified by metals or oxides. Hence, nanostructured BDD electrodes have been fabricated to improve electrochemical performance without sacrificing the favorable properties of diamond. In 2008, Yang et al. ${ }^{18,19}$ reported for the first time the electrochemical application of vertically aligned diamond nanowires fabricated by reactive ion etching with $\mathrm{O}_{2}$ plasma for DNA sensing. Luo et al. ${ }^{20}$ reported the use of vertically aligned diamond nanorods produced by BDD deposition on vertically aligned silicon nanowires for glucose sensing.
In comparison with planar BDD electrodes, the electrodes fabricated by Luo et al. ${ }^{20}$ exhibited a well-defined current response to glucose, although the sensitivity was lower than that of metalmodified BDD electrodes. ${ }^{21}$ These vertically aligned nanostructures exhibited high internal resistances because of their high aspect ratio, which resulted in limited sensitivity. ${ }^{22}$

Recently, researchers have developed high-performance electrochemical sensors using three-dimensional (3D)-networked nanostructures with various materials. ${ }^{23,24}$ These 3D-networked structures are expected to lead to effective electron transport and large surface areas. Lei et al. ${ }^{25}$ developed an electrochemical biosensor based on a $\mathrm{ZnO}$ nanotetrapod network to detect glucose and observed outstanding performance in comparison with other biosensors modified by various quasi-1D $\mathrm{ZnO}$ nanostructures. So far, however, there have been no reports on the synthesis of BDD-based 3D-networked nanostructures and their application to biosensors.

In this study, we attempted to synthesize a porous $3 \mathrm{D} \mathrm{BDD}$ nanostructure using networked multi-walled carbon nanotubes (MWCNTs) as the core by the electrostatic self-assembly of nanodiamond (ESAND) technique. 3D-networked and porous BDD-CNT nanostructures are expected to show good electrochemical properties. Furthermore, core-shell structures including CNTs as the core material are predicted to show enhanced performance because CNTs can provide electron pathways. Because electrochemical glucose sensors have been extensively studied using electrodes modified

${ }^{1}$ Department of Materials Science and Engineering, Korea University, Seongbuk-gu, Seoul, Republic of Korea; ${ }^{2}$ Department of Materials Science and Engineering, Yonsei University, Seodaemun-gu, Seoul, Republic of Korea and ${ }^{3}$ Advanced Analysis Center, Korea Institute of Science and Technology, Cheongryang, Seoul, Republic of Korea ${ }^{4}$ These authors contributed equally to this work.

Correspondence: Professor D-S Lim, Department of Materials Science and Engineering, Korea University, Anam-dong 5-ga, Seoungbuk-gu, Seoul 136-713, Republic of Korea. E-mail: dslim@korea.ac.kr

Received 19 November 2013; revised 23 April 2014; accepted 12 May 2014 
with various materials and nanostructures, the biosensing performances of the BDD-CNT electrodes were evaluated using glucose as the target analyte to enable facile comparison with other related sensors.

\section{MATERIALS AND METHODS}

\section{Materials and chemicals}

Stainless steel 316L (SUS316L) nanoparticles with an average diameter of $100 \mathrm{~nm}$ provided by Nanotechnology (Daejeon, Korea) were used as the catalyst for growing the MWCNTs. Nanodiamond powder with an average particle size of $5 \mathrm{~nm}$ was purchased from Shenzhen Jingangyuan New Material Development (Guangdong, China). Poly(diallyldimethyl ammonium chloride) (PDDA, molecular weight: 100000-200000), poly(sodium 4-styrene sulfonate) (PSS, molecular weight: 70000), D-glucose, and glucose oxidase $\left(\mathrm{GO}_{\mathrm{x}}\right.$; E.C. 1.1.3.4, $\left.200 \mathrm{U} \mathrm{mg}^{-1}\right)$ from Aspergillus niger were obtained from Sigma-Aldrich (St Louis, MO, USA). All the stock solutions were prepared in a $0.05 \mathrm{M}$ phosphate buffer solution at $\mathrm{pH}$ 7.0. The diluted glucose solutions were prepared from a stock solution immediately before use.

\section{CNT synthesis}

Before MWCNTs synthesis, the $\mathrm{SiO}_{2}$ substrate was successively cleaned with acetone, ethanol and deionized (DI) water. The substrate was dipped in 20 $\mathrm{wt} \%$ cationic PDDA aqueous solution for $5 \mathrm{~h}$. Then, the substrate was rinsed with DI water to remove the excessive PDDA and dried with $\mathrm{N}_{2}$ gas. The PDDA-coated substrate was immersed in $35 \mathrm{wt} \%$ anionic PSS aqueous solution for $5 \mathrm{~h}$. After rinsing and drying, the $\mathrm{SiO}_{2} / \mathrm{PDDA} / \mathrm{PSS}$ layer-by-layer structure was obtained. Finally, the substrate was immersed in the cationic SUS316L nanoparticle suspension for $24 \mathrm{~h}$. During this process, the SUS316L nanoparticles spontaneously attached to the PSS layer via electrostatic interactions. The MWCNTs were synthesized by thermal chemical vapor deposition with $\mathrm{C}_{2} \mathrm{H}_{2}(20 \mathrm{sccm}), \mathrm{H}_{2}(100 \mathrm{sccm})$ and $\mathrm{N}_{2}(400 \mathrm{sccm})$ at $750^{\circ} \mathrm{C}$ for $5 \mathrm{~min}$.

\section{Preparation of the 3D-networked BDD-CNT electrode}

To prepare the BDD-CNT core-shell hybrid electrode, the nanodiamond particles were attached to the outer wall of the MWCNTs by ESAND. Before the deposition process, an anionic PSS-coated nanodiamond (PSS-ND) solution was prepared. (The details of the dispersion method are explained in the Supplementary Information section.) The MWCNTs were covered with cationic PDDA and anionic PSS-ND through sequential immersion. Then, the BDD was deposited using a gas mixture consisting of $1 \% \mathrm{CH}_{4}, 0.05 \% \mathrm{~B}_{2} \mathrm{H}_{6}$ and $98.95 \% \mathrm{H}_{2}$ by hot-filament chemical vapor deposition at $850^{\circ} \mathrm{C}$ for $60 \mathrm{~min}$. The total flow rate of the gas mixture was $100 \mathrm{sccm}$, and the pressure was $10 \mathrm{kPa}$

\section{Characterization \\ The surface morphology and atomic structure of the BDD-CNT core-shell nanostructures were characterized by field emission-scanning electron microscopy (Hitachi S-4800, Tokyo, Japan) and transmission electron micro- scopy (TEM) equipped with an electron energy-loss spectroscopy and selective area electron diffraction pattern acquisition apparatus (FEI Titan G2, Hillsboro, OR, USA). Amperometric and impedance measurements were performed using a CompactStat instrument (Ivium technologies, Eindhoven, the Netherlands) connected to a three-electrode cell. The three- electrode system consisted of a platinum wire as the counter electrode, an $\mathrm{Ag} /$ $\mathrm{AgCl}$ electrode as the reference electrode and the modified thin-film electrodes as the working electrode.}

\section{RESULTS AND DISCUSSION}

The fabrication of the BDD-CNT nanowires is illustrated in Figure 1a. MWCNTs with diameters ranging from $50 \mathrm{~nm}$ to $150 \mathrm{~nm}$ acted as a framework. To synthesize the BDD layer on the MWCNTs surface without etching the $s p^{2}$ MWCNTs under the hydrogen-rich
BDD deposition conditions, ${ }^{26,27}$ a minimal area of the MWCNTs should be exposed to the deposition atmosphere to form diamond nucleation sites on the MWCNTs surfaces. For this purpose, we attached a highly dense layer of nanodiamond particles on the MWCNTs surfaces. To attach the nanodiamond particles to the MWCNTs surfaces, which were as thin as $150 \mathrm{~nm}$, a dispersion process was required because the average particle size of the agglomerated nanodiamond was larger than $1 \mu \mathrm{m}$. Nanodiamond particles with cationic surfaces were dispersed by attrition milling in DI water with an anionic PSS dispersion agent. The MWCNTs were dipped in cationic PDDA and anionic PSS-ND solutions by the ESAND technique. ${ }^{28}$ The nanodiamonds covered the outer wall of the MWCNTs framework. After BDD deposition by HFCVD, 3D and porous BDD-CNT core-shell nanowire networks were fabricated (Figure 1b). The as-synthesized nanowires were $100-200 \mathrm{~nm}$ in diameter and consisted of cross-linked MWCNTs covered by BDD nanocrystals (Figure 1c).

The morphologies of the MWCNTs core and the BDD shell were further confirmed by TEM (Figure 2). The initial BDD growth on the MWCNTs core is shown in Figure 2a. The BDD nanocrystals grew along the MWCNTs surfaces. Under the BDD growth conditions employed here, diamond growth and CNT etching are competitive processes. However, the highly dense nanodiamond particles on the MWCNTs surface facilitated BDD growth, suppressing the etching of the MWCNTs by hydrogen radicals. The MWCNTs, which were left untreated by ESAND, were fully etched by the hydrogen radicals and were transformed to graphite clusters during diamond deposition. The nanodiamond-seeded MWCNTs obtained by ESAND were fully covered with BDD, which resulted in a 3D random network and porous structure (see Supplementary Figure S1 in the Supplementary Information). It can be observed from Figure $2 \mathrm{~b}$ that the MWCNTs were fully covered with BDD, without any pin-holes, after BDD deposition for $60 \mathrm{~min}$. The synthesized BDD showed $\{111\}$ lattice fringes oriented parallel to the electron beam (Figure 2c). The BDDCNT core-shell nanowires were analyzed by electron energy-loss spectroscopy (Figure 2d), which shows the features of carbon K-edge spectra. ${ }^{29,30}$ Graphite (or amorphous carbon) and diamond show a distinct absorption edge from the K-shell at the peak related to the carbon phase. The peak at approximately $286 \mathrm{eV}$ corresponded to the $1 s$ to $\pi^{*}$ transition, which can be assigned to the $s p^{2}$-bonded carbon phase present at the grain boundaries of the BDD shell and the MWCNTs core. Further, the BDD-CNT showed a $s p^{3}$-bonded carbon phase and a peak at approximately $291 \mathrm{eV}$ originating from the $1 s$ to $\sigma^{*}$ transition. In the selective area electron diffraction pattern, Bragg reflections were located in each circle, confirming the diamond crystallographic indices of $\{111\},\{220\}$ and $\{311\}$ (Figure 2e). In addition, the spots around each ring were assigned to the polycrystalline phase.

Figure $3 \mathrm{a}$ shows the relative cyclic voltammograms (CVs) of the three different electrodes, that is, the CNT, BDD and BDD-CNT electrodes in a $3 \mathrm{M} \mathrm{KCl}$ solution containing $10 \mathrm{mM} \mathrm{Fe}(\mathrm{CN})_{6}{ }^{3-/ 4-}$. In the case of the CNT electrode, the anodic peak potential $\left(E_{\mathrm{pa}}\right)$ was at $0.567 \mathrm{~V}$ (with a current of $0.3 \mathrm{~mA}$ ), while the cathodic peak potential $\left(E_{\mathrm{pc}}\right)$ was at $-0.03 \mathrm{~V}$ (with a current of $-0.453 \mathrm{~mA}$ ). The peak-to-peak separation $\left(\Delta E_{\mathrm{p}}\right)$ was $0.867 \mathrm{~V}$. For the BDD electrode, the anodic and cathodic peaks were located at $0.454 \mathrm{~V}$ (with a current of $0.565 \mathrm{~mA}$ ) and $0.03 \mathrm{~V}$ (with a current of $-0.886 \mathrm{~mA}$ ), respectively, and the $\Delta E_{\mathrm{p}}$ was $0.424 \mathrm{~V}$. However, the redox peak currents of the BDD-CNT electrode were significantly enhanced, with the oxidation peak current $\left(i_{\mathrm{pa}}\right)$ at $1.65 \mathrm{~mA}\left(E_{\mathrm{pa}}=0.32 \mathrm{~V}\right)$ and the reduction peak current $\left(i_{\mathrm{pc}}\right)$ at $1.74 \mathrm{~mA}\left(E_{\mathrm{pc}}=0.208 \mathrm{~V}\right)$. 
a
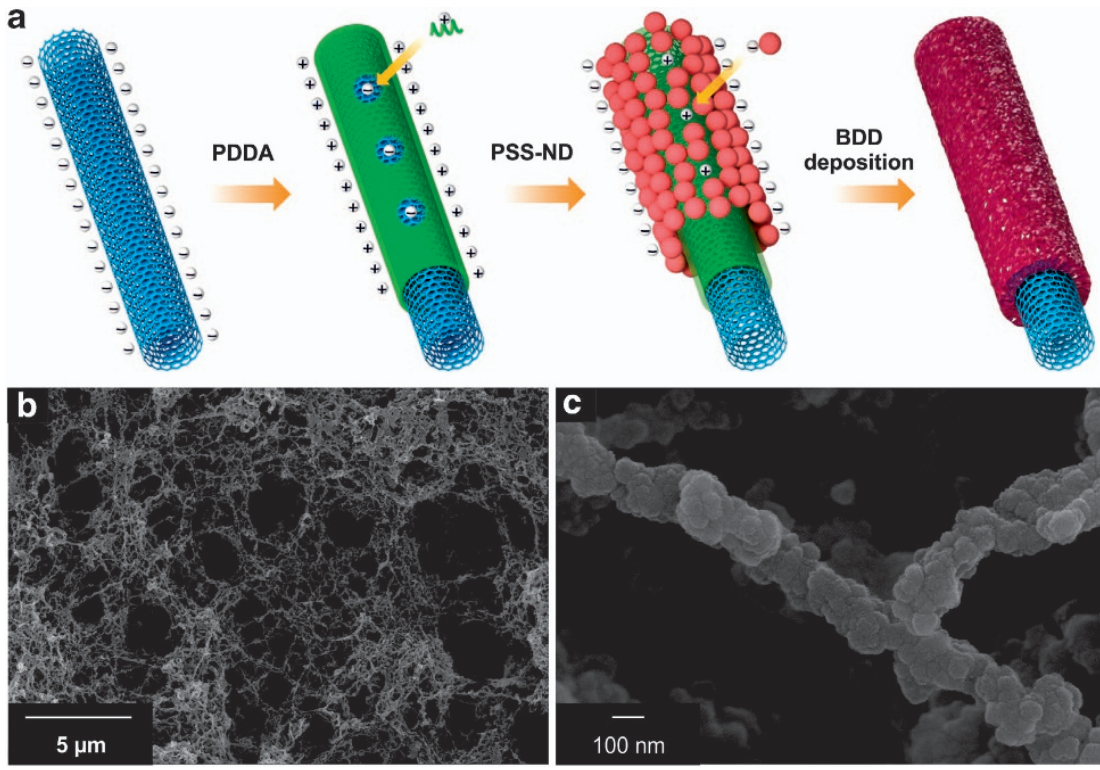

Figure 1 (a) Schematic representation of the BDD-CNT core-shell hybrid nanowire. (b) SEM image of the 3D-networked BDD-CNT nanowires. (c) High-magnification SEM image of the BDD-CNT nanowire.
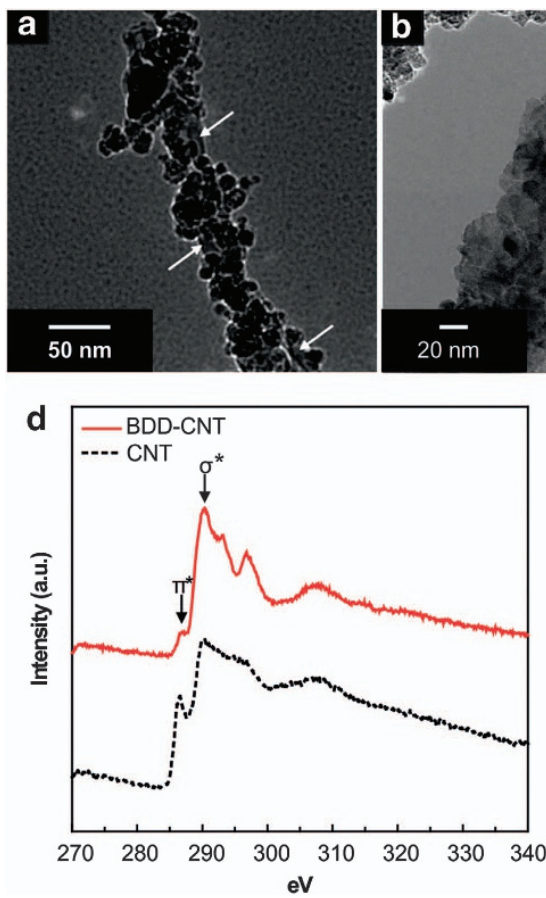
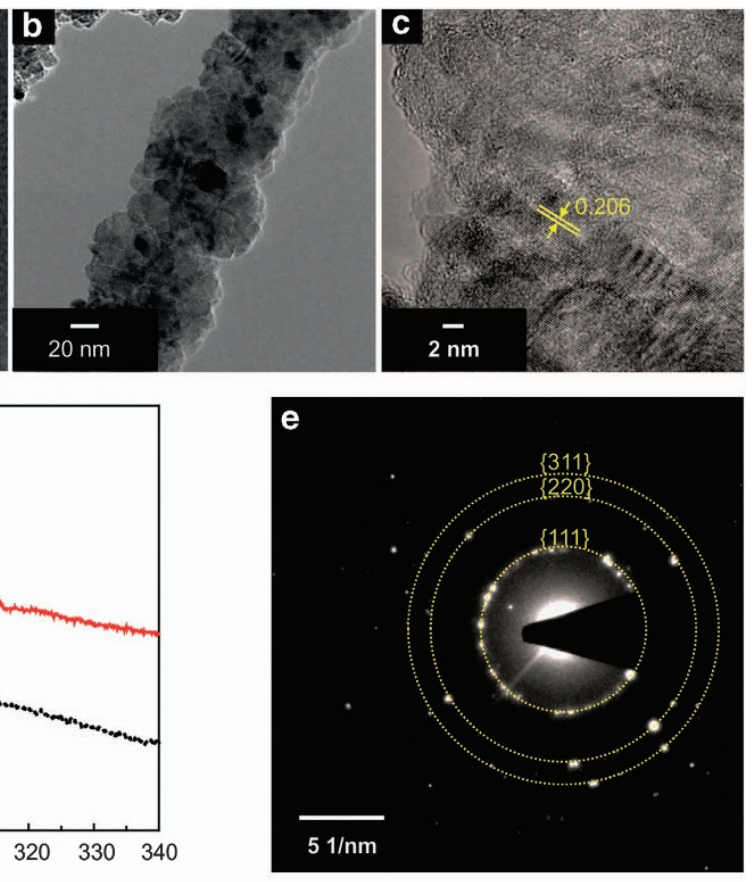

Figure 2 (a) TEM image of the BDD-CNT core-shell nanowire synthesized in $15 \mathrm{~min}$. (The white arrows indicate the MWCNTs core.) (b) TEM image of the BDD-CNT core-shell nanowire synthesized in $60 \mathrm{~min}$. (c) High-resolution TEM image of the BDD-CNT core-shell nanowire. (d) Electron energy-loss spectroscopy profiles of the CNT and BDD-CNT electrodes. (e) Selective area electron diffraction pattern of the BDD-CNT core-shell hybrid nanowire.

The $\Delta E_{\mathrm{p}}$ showed a minimum value of $0.112 \mathrm{~V}$. As shown by the $\mathrm{CVs}$, the well defined and quasi-reversible redox peaks imply effective direct electron transfer between the electrode and the redox species. $^{31}$ The electrochemical response of these different electrodes increased in the order $\mathrm{BDD}-\mathrm{CNT}>\mathrm{BDD}>\mathrm{CNT}$. Hence, the BDD-CNT electrode showed the largest effective surface area compared with the others because the increase in peak current is proportional to the effective surface area. ${ }^{32}$ The morphology of the
CNT electrode was 3D; however, its effective surface area was smaller than those of the other electrodes, which could be attributed to the weak adhesion between the layers, as the CNT nanomaterials were directly grown on a $\mathrm{SiO}_{2}$ substrate. This caused the CNT layer to delaminate from the substrate, making it unstable for use in biosensor applications. The significant enhancement of the signal of the BDD-CNT electrode can be attributed to the synergistic effects of the $3 \mathrm{D}$ nanostructure and the characteristics of the hybrid material, 

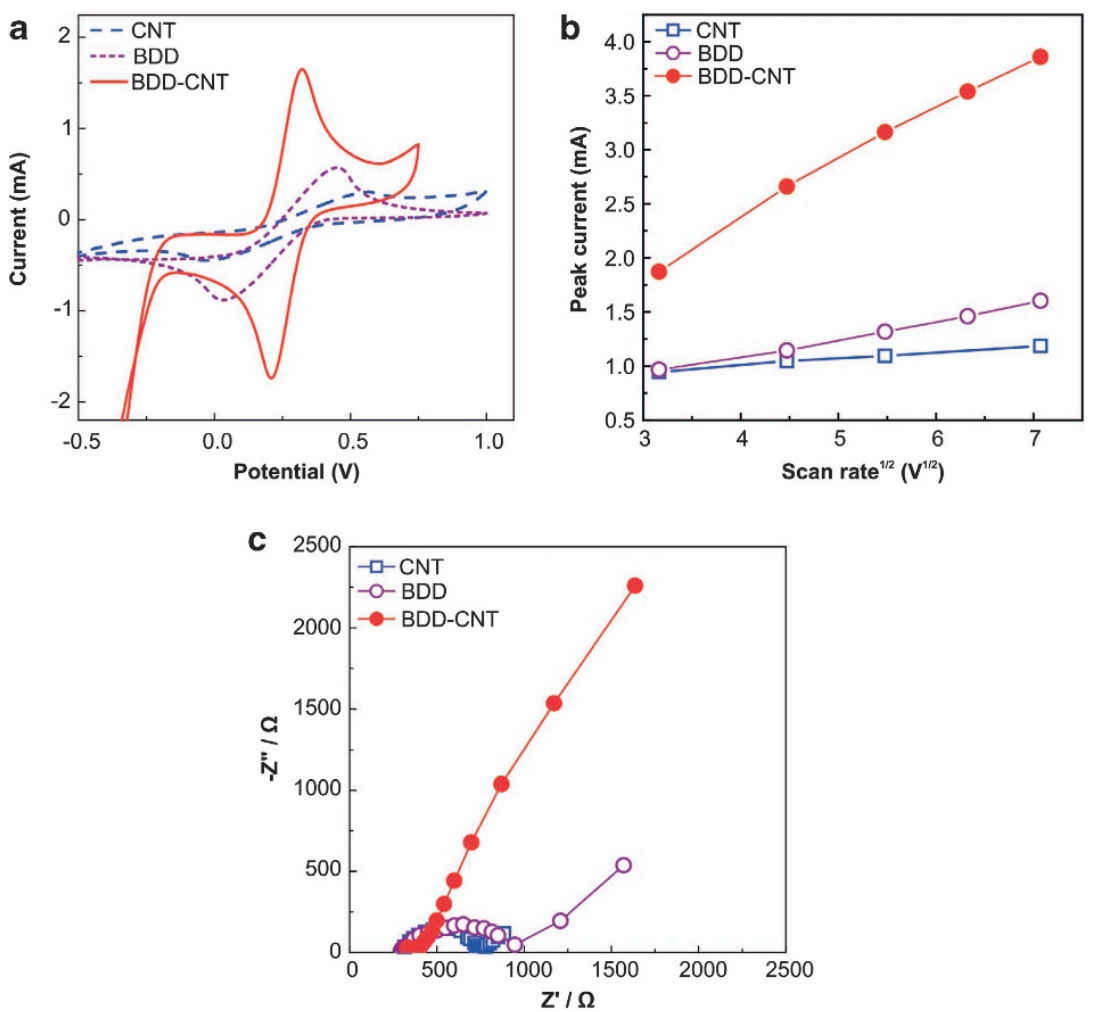

Figure 3 (a) Cyclic voltammograms of CNT, BDD and BDD-CNT electrodes in a $3 \mathrm{M} \mathrm{KCl}$ solution containing $10 \mathrm{mM} \mathrm{Fe}(\mathrm{CN})_{6}{ }^{3-14}-$ at a scan rate of $50 \mathrm{mVs}^{-1}$. (b) Peak currents as a function of scan rate for determining the effective surface areas of the CNT, BDD and BDD-CNT core-shell network electrodes. (c) Nyquist plots for the CNT, BDD and BDD-CNT electrodes in a $0.1 \mathrm{M} \mathrm{KCl}$ solution containing $5 \mathrm{mM} \mathrm{Fe}(\mathrm{CN})_{6}{ }^{3-14-}$.

Table 1 Effective surface areas of the modified electrodes

\begin{tabular}{lccc}
\hline Electrode & $\begin{array}{c}\text { Correlation } \\
\text { coefficient }(\mathrm{R})\end{array}$ & Randles'slope & $\begin{array}{c}\text { Effective electrode } \\
\text { area }\left(\mathrm{cm}^{2}\right)\end{array}$ \\
\hline CNT & 0.9953 & 0.0608 & 0.259 \\
BDD & 0.9981 & 0.1633 & 0.696 \\
BDD-CNT & 0.9971 & 0.5060 & 2.130 \\
\hline
\end{tabular}

Abbreviations: BDD, boron-doped diamond; BDD-CNT, boron-doped diamond-carbon nanotube; CNT, carbon nanotube.

which resulted in electron transfer acceleration and a larger effective surface area.

To identify the effective surface areas of each electrode, the CVs of the modified electrodes were measured at a variety of scan rates in a $3 \mathrm{M} \mathrm{KCl}$ solution containing $10 \mathrm{~mm}_{3} \mathrm{Fe}(\mathrm{CN})_{6}$, and the RandlesSevcik equation was applied. ${ }^{33}$ As shown in equation (1), the effective surface area $(A)$ is proportional to $I_{\mathrm{p}} / v^{1 / 2}$.

$$
I_{\mathrm{p}}=\left(2.69 \times 10^{5}\right) n^{3 / 2} A D_{0}^{1 / 2} C_{0}^{*} v^{1 / 2}
$$

In the above equation, $n$ is the number of electrons participating in the redox reaction, $v$ is the scan rate of the potential perturbation $\left(\mathrm{V} \mathrm{s}^{-1}\right), A$ is the area of the electrode $\left(\mathrm{cm}^{2}\right), D$ is the diffusion coefficient of the molecules in solution $\left(\mathrm{cm}^{2} \mathrm{~s}^{-1}\right), C^{\star}$ is the probe molecule concentration in the bulk solution $\left(\mathrm{mol} \mathrm{cm}^{-3}\right)$ and $I_{\mathrm{p}}$ is the peak current of the redox couple (A). As shown in Figure 3b, $I_{\mathrm{p}}$ showed a linear relationship with the square root of the scan rate $\left(v^{1 / 2}\right)$ for the modified electrodes. Thus, the effective surface area
Table 2 Amperometric glucose biosensor performance of the modified electrodes

\begin{tabular}{lccccc}
\hline & & & Correlation \\
Electrode & Linear ranges $(m M)$ & $\left(\mu A m^{-1}\right)$ & $(\mathrm{R})$ & $\begin{array}{c}\text { coefficient } \\
\text { limit }(\mu M)\end{array}$ \\
\hline CNT & $5.63-56.25$ & 0.215 & 0.9974 & 564 \\
BDD & $0.00000289-0.000188$ & 13.278 & 0.9917 & 0.00072 \\
BDD-CNT & $0.000000654-0.00008375$ & 8720.072 & 0.9932 & 0.00004
\end{tabular}

Abbreviations: BDD, boron-doped diamond; BDD-CNT, boron-doped diamond-carbon nanotube; CNT, carbon nanotube.

was calculated by the Randles-Sevcik equation. The results are summarized in Table 1.

To study the properties of the interface, the modified electrodes were characterized by electrochemical impedance spectroscopy. The typical Nyquist plot of the impedance spectra consisted of a semicircle (at high frequencies) and linear portions (at low frequencies). These corresponded to the electron transfer- and diffusion-limited processes, respectively. The diameter of the semicircle, which is equal to the electron transfer resistance $\left(R_{\mathrm{et}}\right)$, controls the electron transfer kinetics of the redox probe at the electrode interface. ${ }^{31,34}$ To record the electrochemical impedance spectroscopy spectra for the modified electrodes, the following parameters were used: the electrolyte was a $0.1 \mathrm{M} \mathrm{KCl}$ solution containing $5 \mathrm{mM} \mathrm{K}_{3}\left[\mathrm{Fe}(\mathrm{CN})_{6}\right] / \mathrm{K}_{4}\left[\mathrm{Fe}(\mathrm{CN})_{6}\right]$, the frequency range was $10^{-2}-10^{5} \mathrm{~Hz}$, the amplitude potential was $5 \mathrm{mV}$ and the formal potential was $0.23 \mathrm{~V}$. As observed in Figure $3 \mathrm{c}$, each 

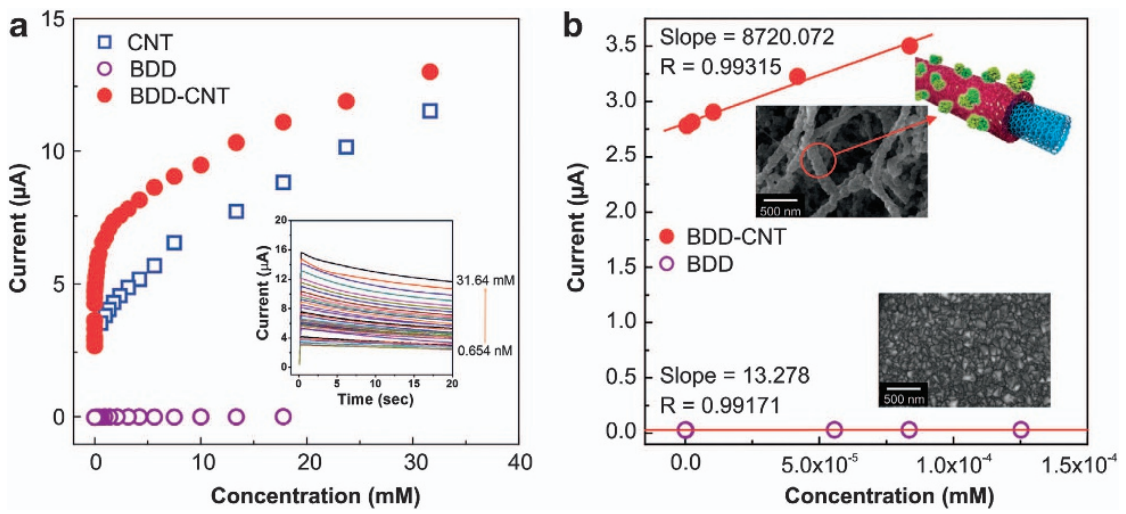

Figure 4 (a) Amperometric current response of the CNT, BDD and BDD-CNT electrodes. Inset: chronoamperometric curves obtained at various concentrations of glucose with the BDD-CNT electrode. (b) Calibration curves of the BDD-based electrodes at low concentrations. Inset: SEM images of the $\mathrm{BDD}$ and BDD-CNT electrodes. (Illustration: $\mathrm{GO}_{\mathrm{x}}$-immobilized BDD-CNT).

Table 3 Comparison of the glucose sensing performances of various nanomaterials

\begin{tabular}{|c|c|c|c|c|}
\hline Electrode type & Linear range $(m M)$ & Sensitivity $\left(\mu A \mathrm{mM}^{-} \mathrm{cm}^{-2}\right)$ & Detection limit $(\mu M)$ & Reference \\
\hline $\mathrm{GO}_{x} / \mathrm{ZnONFs} / \mathrm{Au}$ & $0.25-19$ & 70.2 & 1.0 & 37 \\
\hline $\mathrm{GO}_{\mathrm{X}} / \mathrm{PtNPd} / \mathrm{PAni} / \mathrm{Pt}$ & $0.01-8$ & 96.1 & 0.7 & 39 \\
\hline 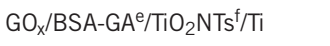 & $0.05-0.65$ & 199.6 & 3.8 & 40 \\
\hline $\mathrm{GO}_{\mathrm{x}} / \mathrm{BDD}-\mathrm{CNT} / \mathrm{SiO}_{2}$ & $0.000000654-0.00008375$ & 3841.78 & 0.00004 & This work \\
\hline
\end{tabular}

Abbreviations: BDD, boron-doped diamond; BDD-CNT, boron-doped diamond-carbon nanotube; CNT, carbon nanotube; GO, glucose oxidase; GCE, glassy carbon electrode; ITO, indium tin oxide.

aSilver nanoparticles.

binc oxide nanofibers.

'Gold core/silver shell nanorods.

dPlatinum nanoparticle.

eBovine serum albumin-glutaraldehyde.

${ }^{\mathrm{f}}$ Titanium oxide nanotubes.

of the samples showed depressed semicircles at high frequencies. This phenomenon can be explained by the existence of the constant phase element, which is substituted with the electrical double-layer capacitance. The constant phase element originates from inhomogeneities on the electrode surface, such as porosity, surface roughness, variations in composition and interference from functional molecules. The value of $R_{\mathrm{et}}$ for these electrodes followed the order BDD (approximately $750 \Omega$ ) $>$ CNT (approximately $430 \Omega$ ) $>$ BDD-CNT (approximately $10 \Omega$ ). The BDD-CNT layer was able to produce good electron transfer between the electroactive sites and the electrode owing to the ability of the 3D-networked, CNT-modified electrode to promote electron transfer reactions. ${ }^{35}$ Thus, the BDD-CNT electrode showed enhanced electron transport properties and a large effective surface area.

To compare the performances of the modified electrodes, glucose was used as a target analyte and $\mathrm{GO}_{\mathrm{x}}$ was immobilized on each electrode by covalent bonding (Supplementary Figure S4 in the Supplementary Information). Figure $4 \mathrm{a}$ shows the response curves of the modified electrodes at various glucose concentrations and an applied potential of $+0.6 \mathrm{~V}$. The CNT electrode showed a sensitivity similar to that of the BDD-CNT electrode at high glucose concentrations (5-56 mM). Both the BDD-CNT and BDD electrodes showed enhanced sensitivities at low concentrations (Figure $4 \mathrm{~b}$ ); however, the BDD-based electrodes were able to detect lower glucose concentrations than the CNT electrodes because of their unique material properties, which allowed a wide potential window and a low background current. The sensing performances of the modified electrodes are outlined in Table 2. The sensitivity of the BDD-CNT electrode was 657 times higher than that of the planar BDD electrode at very low concentrations of glucose. The inset in Figure 4a shows the resulting current curves for each concentration of glucose. The current curves of the BDD-CNT electrode indicate a sufficiently high signal-to-noise ratio even at very low concentrations of glucose $(0.654 \mathrm{~nm})$. In addition, the response time of the BDD-CNT electrode, which is defined as the time needed to reach $90 \%$ of the saturated current value, was less than $10 \mathrm{~s}$. The analytical performance of the sensor was compared with those of other glucose biosensors reported in the literature (Table 3). ${ }^{36-40}$ The BDD-CNT electrode exhibited high sensing performance at very low glucose concentration ranges and showed a wider linear range, a higher sensitivity per unit area and a lower detection limit than those of other sensors. Its enhanced performance can be attributed to the synergistic effects of the BDDbased hybrid nanomaterial and the 3D-networked nanostructure.

The reproducibility of the sensors based on the BDD-CNT electrode was investigated at five different concentrations of glucose using three different sensors. The relative standard deviation for each concentration was below $4 \%$, which indicated good reproducibility (see Supplementary Table S1 in the Supplementary Information).

Recently, noninvasive measurements of glucose concentrations in humans using biofluids with lower glucose concentrations than those in blood (such as saliva, tears and sweat) has gained considerable attention. ${ }^{41}$ In addition, the measurement of glucose at very low 
concentrations (approximately several tens of nanomolar) is useful to estimate complex microbial populations, such as bacteria in sea water. $^{42}$ Consequently, the BDD-CNT electrode developed in this study, which exhibits high sensitivity at low concentration ranges, shows promise for the noninvasive measurement of glucose in living beings as well as for environmental monitoring in sea water.

\section{CONCLUSIONS}

In this study, a core-shell BDD-CNT nanowire with a 3D network structure was developed, and its basic electrochemical properties were characterized using CVs and electrochemical impedance spectroscopy and compared with the performances of the bare BDD film and CNTs. During the synthesis of the BDD-CNT structure, the densely attached nanodiamond particles played an important role in preventing the etching of the MWCNTs and promoting BDD growth. In comparison to other electrodes, the BDD-CNT electrode exhibited better electrochemical performance, that is, a low electron transfer resistance, a large effective surface area and high sensitivity with a remarkably low detection limit $\left(8.7 \mu \mathrm{Amm}^{-1}\right.$ in the range of $0.65-$ $83.75 \mathrm{~nm}$ ). The improvement in the performances of the BDD-CNT electrode could be attributed to the geometry and electron pathways provided by the CNTs as well as to the synergistic effects of the BDD and CNTs. Our results indicate that the BDD-CNT electrode may be potentially applied in the electrochemical detection of analytes at very low concentrations, specifically in next-generation glucose sensors.

\section{CONFLICT OF INTEREST}

The authors declare no conflict of interest.

\section{ACKNOWLEDGEMENTS}

This study was supported by the MSPI (The Ministry of Science, ICT and Future Planning), Korea, under the ICT R\&D Infrastructure Support Program (NIPA-2014-I2218-13-1001) supervised by the NIPA (National IT Industry Promotion Agency); by the Priority Research Centers Program (2009-0093823) through the National Research Foundation of Korea (NRF); by the Hi Seoul Science Fellowship from Seoul Scholarship Foundation; by the second stage of the Brain Korea 21 Project in 2012; and by a Korea University Grant.

1 Carlisle, J. A. Diamond films: precious biosensors. Nat. Mater. 3, 668-669 (2004).

2 Nebel, C. E., Shin, D., Rezek, B., Tokuda, N., Uetsuka, H. \& Watanabe, H. Diamond and biology. J. R. Soc. Interface 4, 439-461 (2007).

3 Kraft, A. Doped Diamond: a compact review on a new, versatile electrode material. Int. J. Electrochem. Sci. 2, 355-385 (2007).

4 Strojek, J. W., Granger, M. C., Swain, G. M., Dallas, T. \& Holtz, M. W. Enhanced signalto-background ratios in voltammetric measurements made at diamond thin-film electrochemical interfaces. Anal. Chem. 68, 2031-2037 (1996).

5 Yang, W., Auciello, O., Butler, J. E., Cai, W., Carlisle, J. A., Gerbi, J. E., Gruen, D. M., Knickerbocker, T., Lasseter, T. L., Russell, J. N. Jr \& Hamers, R. J. DNA-modified nanocrystalline diamond thin-films as stable, biologically active substrates. Nat. Mater 1, 253-257 (2002)

6 Härtl, A. Schmich, E., Garrido, J. A., Hernando, J., Catharino, S. C. R., Walter, S., Feulner, P., Kromka, A., Steinmüller, D. \& Stutzmann, M. Protein-modified nano crystalline diamond thin films for biosensor applications. Nat. Mater. 3, 736-742 (2004)

7 Stavis, C., Clare, T. L., Butler, J. E., Radadia, A. D., Carr, R., Zeng, H., King, W. P., Carlisle, J. A., Aksimentiev, A., Bashir, R. \& Hamers, R. J. Surface functionalization of thin-film diamond for highly stable and selective biological interfaces. Proc. Natl Acad. Sci. USA 108, 983-988 (2011).

8 Tang, L., Tsai, C., Gerberich, W. W., Kruckeberg, L. \& Kania, D. R. Biocompatibility of chemical-vapour-deposited diamond. Biomaterials 16, 483-488 (1995).

9 Garrido, J. A., Härtl, A., Dankerl, M., Reitinger, A., Eickhoff, M., Helwig, A., Müller, G. \& Stutzmann, M. The surface conductivity at the diamond/aqueous electrolyte interface. J. Am. Chem. Soc. 130, 4177-4181 (2008).

10 Patten, H. V., Meadows, K. E., Hutton, L. A., lacobini, J. G., Battistel, D., Mckelvey, K., Colburn, A. W., Newton, M. E., Macpherson, J. V. \& Unwin, P. R. Electrochemical mapping reveals direct correlation between heterogeneous electron-transfer kinetics and local density of states in diamond electrodes. Angew. Chem. Int. Ed. 51, 7002-7006 (2012)

11 Ferro, S. \& De Battisti, A. The 5-V window of polarizability of fluorinated diamond electrodes in aqueous solutions. Anal. Chem. 75, 7040-7042 (2003).

12 Szunerits, S., Jama, C., Coffinier, Y., Marcus, B., Delabouglise, D. \& Boukherroub, R. Direct amination of hydrogen-terminated boron doped diamond surfaces. Electrochem. Commun. 8, 1185-1190 (2006).

13 Weng, J., Xue, J., Wang, J., Ye, J., Cui, H., Sheu, F. \& Zhang, Q. Gold-cluster sensors formed electrochemically at boron-doped-diamond electrodes: detection of dopamine in the presence of ascorbic acid and thiols. Adv. Funct. Mater. 15, 639-647 (2005).

14 Batchelor-McAuley, C., Banks, C. E., Simm, A. O., Jones, T. G. J. \& Compton, R. G. The electroanalytical detection of hydrazine: a comparison of the use of palladium nanoparticles supported on boron-doped diamond and palladium plated BDD microdisc array. Analyst 131, 106-110 (2006)

15 Bonne, M. J., Helton, M., Edler, K. \& Marken, F. Electro-deposition of thin cellulose films at boron-doped diamond substrates. Electrochem. Commun. 9, 42-48 (2007)

$16 \mathrm{Gu}, \mathrm{H}$., di Su, X. \& Loh, K. P. Electrochemical impedance sensing of DNA Hybridization on conducting polymer film-modified diamond. J. Phys. Chem. B 109, 13611-13618 (2005).

17 Ivandini, T. A., Sato, R., Makide, Y., Fujishima, A. \& Einaga, Y. Electroanalytical application of modified diamond electrodes. Diam. Relat. Mater. 13, 2003-2008 (2004)

18 Yang, N., Uetsuka, H., Osawa, E. \& Nebel, C. E. Vertically aligned diamond nanowires for DNA sensing. Angew. Chem. Int. Ed. 47, 5183-5185 (2008).

19 Yang, N., Uetsuka, H., Osawa, E. \& Nebel, C. E. Vertically aligned nanowires from boron-doped diamond. Nano Lett. 8, 3572-3576 (2008).

20 Luo, D., Wu, L. \& Zhi, J. Fabrication of Boron-doped diamond nanorod forest electrodes and their application in nonenzymatic amperometric glucose biosensing. ACS Nano 3 2121-2128 (2009).

21 Toghill, K. E., Xiao, L., Phillips, M. A. \& Compton, R. G. The non-enzymatic determination of glucose using an electrolytically fabricated nickel microparticle modified boron-doped diamond electrode or nickel foil electrode. Sens. Actuator B-Chem. 147, 642-652 (2010).

22 Song, M. J., Hwang, S. W. \& Whang, D. Non-enzymatic electrochemical $\mathrm{CuO}$ nanoflowers sensor for hydrogen peroxide detection. Talanta 80, 1648-1652 (2010).

23 Dong, C., Xu, H., Wang, X., Huang, Y., Chan-Park, M. B., Zhang, H., Wang, L., Huang, W. \& Chen, P. 3D graphene-cobalt oxide electrode for high-performance supercapacitor and enzymeless glucose detection. ACS Nano 6, 3206-3213 (2013).

24 Niu, X., Lan, M., Zhao, H. \& Chen, C. Highly sensitive and selective nonenzymatic detection of glucose using three-dimensional porous nickel nanostructures. Anal. Chem. 85, 3561-3569 (2013).

25 Lei, Y., Yan, X., Luo, N., Song, Y. \& Zhang, Y. ZnO nanotetrapod network as the adsorption layer for the improvement of glucose detection via multiterminal electronexchange. Colloid Surf. A-Physicochem. Eng. Asp. 361, 169-173 (2010).

26 May, P. W. Diamond thin films: a 21st-century material. Phil. Trans. R. Soc. Lond. A 358, 473-495 (2000).

27 Zhang, G., Qi, P., Wang, X., Lu, Y., Mann, D., Li, X. \& Dai, H. Hydrogenation and hydrocarbonation and etching of single-walled carbon nanotubes. J. Am. Chem. Soc $128,6026-6027$ (2006).

28 Lee, S., Kim, J., Jeong, M., Song, M. \& Lim, D. Direct deposition of patterned nanocrystalline CVD diamond using an electrostatic self-assembly method with nanodiamond particles. Nanotechnology 21, 505302 (2010).

29 Dubrovinskaia, N., Wirth, R., Wosnitza, J., Papageorgiou, T., Braun, H. F., Miyajima, N. \& Dubrovinsky, L. An insight into what superconducts in polycrystalline boron-doped diamonds based on investigations of microstructure. Proc. Natl Acad. Sci. USA 105, 11619-11622 (2008).

30 El-Barbary, A. A., Trasobares, S., Ewels, C. P., Stephan, O., Okotrub, A. V., Bulusheva, L. G., Fall, C. J. \& Heggie, M. I. Electron spectroscopy of carbon materials: experiment and theory. J. Phys.: Conf. Ser. 26, 149-152 (2006).

31 Kang, X., Wang, J., Wu, H., Aksay, I. A., Liu, J. \& Lin, Y. Glucose oxidase-graphenechitosan modified electrode for direct electrochemistry and glucose sensing. Biosens. Bioelectron. 25, 901-905 (2009).

32 Upadhyay, S., Rao, G. R., Sharma, M. K., Bhattacharya, B. K., Rao, V. K. \& Vijayaraghavan, R. Immobilization of acetylcholineesterase-choline oxidase on a gold-platinum bimetallic nanoparticles modified glassy carbon electrode for the sensitive detection of organophosphate pesticides, carbamates and nerve agents. Biosens. Bioelectron. 25, 832-838 (2009).

33 Bard, A. J. \& Faulkner, L. R. In Electrochemical Methods: Fundamentals and Applications. 2nd ed. Ch. 6, 226-260 (John Wiley \& Sons, NY, USA, 2001).

34 Suni, I. I. Impedance methods for electrochemical sensors using nanomaterials. Trends Anal. Chem. 27, 604-611 (2008).

35 Cai, C. \& Chen, J. Direct electron transfer of glucose oxidase promoted by carbon nanotubes. Anal. Biochem. 332, 75-83 (2004).

36 Lin, J., He, C., Zhao, Y. \& Zhang, S. One-step synthesis of silver nanoparticles/carbon nanotubes/chitosan film and its application in glucose biosensor. Sens. Actuator B-Chem. 137, 768-773 (2009).

37 Ahmad, M., Pan, C., Luo, Z. \& Zhu, J. A Single ZnO nanofiber-based highly sensitive amperometric glucose biosensor. J. Phy. Chem. C 114, 9308-9313 (2010).

38 Yang, X., Wang, Y., Liu, Y. \& Jiang, X. A sensitive hydrogen peroxide and glucose biosensor based on gold/silver core-shell nanorods. Electrochim. Acta 108, 39-44 (2013). 
39 Zhai, D., Liu, B., Shi, Y., Pan, L., Wang, Y., Li, W., Zhang, R. \& Yu, G. Highly sensitive glucose sensor based on Pt nanoparticle/polyaniline hydrogel heterostructures. ACS Nano 7, 3540-3546 (2013).

40 Wang, W., Xie, Y., Wang, Y., Du, H., Xia, C. \& Tian, F. Glucose biosensor based on glucose oxidase immobilized on unhybridized titanium dioxide nanotube arrays. Microchim. Acta 181, 381-387 (2014).

41 Kostov, Y., Ge, X., Rao, G. \& Tolosa, L. Portable system for the detection of micromolar concentrations of glucose. Meas. Sci. Technol. 25, 025701 (2014).

42 Alonso, C. \& Pernthaler, J. Roseobacter and SAR11 dominate microbial glucose uptake in coastal North Sea waters. Environ. Microbiol. 8, 2022-2030 (2006). (c) (i) (2) (2) This work is licensed under a Creative Commons Attribution-NonCommercial-ShareAlike 3.0 Unported License. The images or other third party material in this article are included in the article's Creative Commons license, unless indicated otherwise in the credit line; if the material is not included under the Creative Commons license, users will need to obtain permission from the license holder to reproduce the material. To view a copy of this license, visit http://creativecommons.org/licenses/by-nc-sa/3.0/

Supplementary Information accompanies the paper on the NPG Asia Materials website (http://www.nature.com/am) 